\title{
Article
}

\section{Comparability of signed and spoken languages: Absolute and relative modality effects in cross-modal typology}

\author{
Zeshan, Ulrike and Palfreyman, Nick
}

Available at https://clok.uclan.ac.uk/31255/

Zeshan, Ulrike orcid iconORCID: 0000-0002-8438-3701 and Palfreyman, Nick orcid iconORCID: 0000-0002-9095-4937 (2020) Comparability of signed and spoken languages: Absolute and relative modality effects in cross-modal typology. Linguistic Typology, 24 (3). pp. 527-562. ISSN 1430-0532

It is advisable to refer to the publisher's version if you intend to cite from the work. http://dx.doi.org/10.1515/lingty-2020-2059

For more information about UCLan's research in this area go to http://www.uclan.ac.uk/researchgroups/ and search for <name of research Group>.

For information about Research generally at UCLan please go to http://www.uclan.ac.uk/research/

All outputs in CLoK are protected by Intellectual Property Rights law, including Copyright law. Copyright, IPR and Moral Rights for the works on this site are retained by the individual authors and/or other copyright owners. Terms and conditions for use of this material are defined in the policies page.

\section{CLoK}

Central Lancashire online Knowledge www.clok.uclan.ac.uk

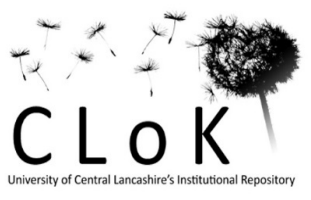




\title{
Comparability of signed and spoken languages: Absolute and relative modality effects in cross-modal typology
}

\author{
Ulrike Zeshan and Nick Palfreyman, University of Central Lancashire
}

\section{Introduction}

Linguistic typology is currently at an important threshold. For the first time in its history, we have come to a point where a substantial amount of data is now available on a range of diverse sign languages. This diversity encompasses various factors including the geographical spread of documented sign languages, their diverse sociolinguistic settings in sign language user communities, as well as their age and developmental path. The considerable expansion in sign language research means that typologists can now start a quest for understanding comparative data from spoken (auditory-vocal) and signed (visualgestural) languages, i.e. cross-modal data, in new ways. This article focuses on the notion of modality effects in cross-modal comparisons. This is a framework for considering typological patterns, including some possible profound differences, between signed and spoken languages in the context of a substantially improved data base.

Before we begin addressing cross-modal comparison, it is helpful to review the state-of-the-art that research on diverse sign languages and comparison between sign languages has reached. Research on sign languages began in earnest in the 1960s, and over the intervening years research has been conducted in all the major subfields of linguistic analysis (McBurney 2012: 923). The sign languages that we discuss in this article are among the primary languages of communication in the communities where they are used, having emerged naturally in those communities over varying lengths of time.

Within sign language research, linguists and sociolinguists are increasingly paying attention to the notion that 'sign languages', while sharing a modality, do not comprise a homogeneous category. Most of the sign languages that linguists began to document in the second half of the twentieth century are from a similar sociolinguistic setting, having arisen primarily among deaf people. These languages owe their existence in many cases to schools for deaf children, which brought together critical masses of users of a certain age and created peer-to-peer transmission paths (Senghas 2005), while the postschool networks that they facilitated enabled further socialization of language (Quinn 2010, Palfreyman 2019). In addition, smaller numbers of deaf and hearing children acquire sign languages as first languages from deaf parents, and this pathway has also played an important role in language transmission. ${ }^{1}$

Since the turn of the present century, sign language researchers have documented a number of radically different sociolinguistic settings where 'shared sign languages' have evolved among deaf and hearing people, due to the long-standing presence of hereditary deafness in small rural communities (Zeshan \& de Vos 2012). ${ }^{2}$ Some of these sign languages, such as Kata Kolok (lit. 'deaf talk') in Bali, appear to have produced similar linguistic outcomes to the 'school-based' sign languages mentioned above, and may have a comparable time-depth (de Vos 2012). However, the sociolinguistic and historical profiles of other rural or village communities using sign languages are much less clear, and as a result, their status can be difficult to determine (Nyst 2012).

Over the past 15 years, Sign Language Typology has developed as a separate sub-discipline of linguistic typology, beginning with a study of interrogative and negative constructions across sign languages (Zeshan 2004, 2006). After this kick-off point, there have been similar large-scale sign language studies on possession and existence (Zeshan \& Perniss 2008), and the semantic domains of colour, kinship, and

\footnotetext{
${ }^{1}$ It is often noted in the sign language literature that the vast majority of deaf children have hearing parents (see for example Costello et al. 2008).

${ }^{2}$ Several sign languages discussed in Section 2 belong to this group, namely Alipur Sign Language (India), Mardin Sign Language (Turkey), and Chican Sign Language (Mexico). For a detailed account of such cases, see Zeshan \& de Vos (2012).
} 
quantification (Zeshan \& Sagara 2016), each covering around three dozen sign languages. The methodologies for these studies have evolved from being largely questionnaire-based, to combinations of typological questionnaires and linguistic elicitation games, as well as moving from English as the only meta-language in typological projects to a combination of English and International Sign. ${ }^{3}$ Researchers at Charles University in Prague are currently using a similar approach to study calendric terms across 21 sign languages. ${ }^{4}$

There have been further typological studies of sign languages in recent years, based on smaller crosslinguistic samples, and/or relying substantially on available published sources rather than specifically collected primary data. These include Pfau \& Steinbach (2006) on pluralization, as well as Pfau, Steinbach \& Herrmann (2016) on subordination, Oomen \& Pfau (2017) on negation, and Zeshan \& Palfreyman (2019) on sensory perception metaphors. Zeshan \& de Vos (2012) is a study of 10 rural sign languages and includes both linguistic and sociolinguistic/anthropological primary data. Rural sign languages are also the focus of de Vos \& Pfau (2015). Some early attempts at conceptualizing sociolinguistic parameters for sign languages that could be used comparatively have also been made, although there are no studies yet that include larger samples of sign languages. Schembri et al. (2018) draw a basic distinction between macro-communities and micro-communities. Palfreyman (2019) presents details of sociolinguistic mapping and parameters for Indonesian Sign Language, which is a promising methodology for collecting primary sociolinguistic data from other sign languages.

The relative scarcity of large-scale typological studies on sign languages is partly due to the complexities of undertaking such research, as this kind of work requires a large international network of coresearchers, including those in countries where sign language research is only just establishing itself, as well as many poorly resourced countries in the global South. Another factor is that we barely have any comprehensive grammatical accounts of individual sign languages to date that could be used for typological research in the way that this has been done for spoken languages using reference grammars (McKee (2015) on New Zealand Sign Language, and Tang (in prep.) on Hong Kong Sign Language are among the few exceptions). Similarly, there are few sign language corpora that could underpin more robust research on individual sign languages, although corpus-based sign language research has made large strides in past years (see Crasborn 2010 about the Sign Linguistics Corpora Network, for example). Some promising developments are currently under way in these areas (see Section 4). When evaluating the various themes, domains and examples discussed throughout this article, we must bear in mind that the analytic base from research on individual sign language is often not as strong as might be expected by readers from outside the sign linguistics discipline.

Notwithstanding these limitations, Sign Language Typology itself has reached a certain level of maturity, and as data from an ever-increasing number of sign languages become available for comparative studies, the next logical step forward is to undertake systematic comparisons between signed and spoken languages on a larger scale. Of course, sign language linguists have always considered issues of modality differences right from the beginning of the field, but systematically framed, large-scale, and empirically substantiated comparison across language modalities has only recently become possible. We call this line of investigation cross-modal typology, i.e. typological research in linguistics that takes into account the differences and the commonalities that exist both between languages and across the two modalities of signed and spoken language. This undertaking was first explicitly conceptualised in work by Zeshan et al. (2013), Zeshan (2017), and Zeshan \& Palfreyman (2017).

In this article, we first address various types of modality effects in Section 2, and propose categorisations that contribute to a framework for cross-modal typology. We also discuss some of the issues and challenges that confront typologists when studying such cross-modal data and their associated typological patterns, including the question of what exactly we mean by the signed and spoken modalities. We then turn to a particular domain in order to exemplify cross-modal comparison with a detailed case study (Section 3). This case study includes data on sensory perception metaphors from 24

\footnotetext{
${ }^{3}$ International Sign is a semi-conventionalised pidgin used in conversations between deaf people from different countries, particularly during international events such as the congresses and conferences of the World Federation of the Deaf, international deaf youth programmes such as 'Frontrunners', international sports events such as Deaflympics, and the like (see Supalla \& Webb 1995; Whynot 2016).

4 See https://ujkn.ff.cuni.cz/en/research/calendric-terms/ [accessed 03 November 2019]
} 
sign languages (Zeshan \& Palfreyman 2019). The study is centrally concerned with semantics and argues for modality effects based on the differential ways in which a linguistic entity's form relates to its meaning in the signed and the spoken modality. Along the way, some deep issues around the nature of the phoneme-morpheme distinction across modalities are also raised, as the role of iconicity in the sublexical structure of signs and words is one of the major challenges in cross-modal typology. Finally, we draw some conclusions for future work in Section 4.

\section{Modality effects}

Modality effects have long been an issue for sign language linguists (for examples see the chapters in Meier et al 2002). When attempting to map out the conceptual framework of cross-modal typology, these effects are central to the discussion, as demonstrated by Zeshan et al (2013), Zeshan \& Palfreyman (2017) and Zeshan (2017). The basic idea is that the language modality - auditory-vocal or visualgestural - influences linguistic structures in different ways. However, there is a certain logical tension between the argument for full functional equivalence between signed and spoken modalities, and the occurrence of differential patterns that could be driven by the language modality. Accordingly, Section 2.1 argues for at least two different perspectives that reflect this tension. In Section 2.2, we present a typology of modality effects, exemplifying the differences between relative and absolute modality effects.

Finally, Section 2.3 goes into some details regarding the analytical issues and challenges that present themselves when signed and spoken languages are compared within this framework. Some of the challenges arise from the fact that the research community has not yet gained experience with making analytical judgments about the kinds of arguments involved in discussing cross-modal typological data. As we shall see, shifting our choices of what is to be compared is prone to changing the results, and the soundness of the argumentation about such choices can be difficult to judge as long as cross-modal typology has not yet developed as a mature sub-discipline with a commonly understood body of work.

\subsection{Approaching the comparability of signed and spoken languages}

Approaching the issue of cross-modal comparison begins with an initial choice as to the overall perspective taken. On the one hand, we may expect, as our initial assumption, that the two language modalities fulfil largely equivalent communicative functions for their user communities, entailing a largely equivalent spread of typological variation. In this view, any typological differences between the modalities would be superficial, to be resolved at a more abstract level, and would be relatively unimportant in comparison with underlying, universal properties of human language. This approach would encourage a more focused analytical effort towards finding generalisable patterns across both modalities, even where the available data suggest that there may be modality differences. It can be assumed that this approach would appeal to linguists who are interested in the general cognitive architecture that enables human language.

At first sight, it seems counter-intuitive not to assume any effects on linguistic structures from the language modality. After all, the three-dimensional gestural signal looks so different from the sound signal, and the neuro-biological foundations of visual perception are different from the perception of speech sounds. However, there are two possible arguments in support of this approach. First of all, research has long demonstrated the substantial parallels between signed and spoken languages with regard to language acquisition and language processing (e.g. Lillo-Martin 1999, Poizner, Klima \& Bellugi 1990). Secondly, typological research on sign languages so far has uncovered many parallels between signed and spoken languages, including when working with larger samples of diverse sign languages.

Some of these parallels include close associations between the expression of location, existence, and possession (Zeshan \& Perniss 2008), and more particularly, the applicability of several of the source constructions for possession proposed in Heine (1997) to sign languages. Research on grammaticalisation in sign languages has also shown such parallels, for example with respect to Jespersen's cycle in sign language negation (Pfau \& Steinbach 2013), and the grammaticalisation of auxiliary constructions from verbal and pronominal source constructions (Pfau \& Steinbach 2011). In these cases, it seems that general cognitive mechanisms are at play which cut across both language 
modalities. However, we also find various typological differences, some of which are exemplified further below in this section.

The second perspective foregrounds the view that despite functional equivalence between languages from the two different modalities, the encoding of communicative functions in terms of linguistic structures and constructions correlates at least partly with the language modality. Hence we expect modality effects of various kinds to occur, and substantial analytical effort will be directed towards identifying and understanding these effects. This approach may appeal to linguists who are concerned with the 'embodiment' of language, because 'embodiment links the individual sensorimotor experiences with higher cognitive functions such as language processing and comprehension' (Jirak et al. 2010:711).

A different line of argumentation comes from researchers who argue for weakening the distinction between what traditionally counts as 'linguistic' material, and other human semiotic capacities such as co-speech gesture, or composite utterances consisting of speech and other meaning-making mechanisms (see Enfield 2013 on composite utterances, Green 2016 on diagramming or drawing, and Hodge et al. 2019 on semiotic diversity more generally). Such considerations naturally lead us to expect that the modalities of signed and spoken languages have different affordances in terms of their semiotic potential. These different semiotic potentials not only support the perspective where cross-modal typological differences are highlighted, but at the same time, this issue constitutes one of the major conceptual challenges to the enterprise of cross-modal typology. The implications of multimodality (particularly with respect to spoken language) in the context of cross-modal typology entail difficult methodological choices, as discussed below.

The approach that foregrounds modality effects has another variant, in which it may be argued that sign languages are not different from spoken languages per se, but pattern with particular sub-types of spoken languages. For instance, similarities between creoles and sign languages have been raised repeatedly in sign language linguistics (e.g. Fischer 1978; Deuchar 1986; Lupton \& Salmons 1996; Bakker 2015) and draw upon certain sociolinguistic parallels between communities of spoken creoles and sign language using communities, 5 including the young age of these languages, their patterns of acquisition, and their historical development. This view highlights the assumption that sociolinguistic conditions of language development and use drive certain cross-modal typological patterns; the 'young languages' would then include the sub-group of spoken creole languages together with sign languages, as opposed to the remaining spoken languages. ${ }^{6}$ Another possibility, which has not yet been explored in the literature, would be to explore typological commonalities between sign languages and those spoken languages that make extensive use of sound symbolism, since in both cases we can observe the effects of meaningful elements at the phonological level. This issue is discussed further in Section 3.

Figure 1 summarises the options with respect to the underlying approach to cross-modal comparison. Within the second approach, the scenario whereby typological differences between signed and spoken languages are genuinely due to the language modality can be said to involve direct modality effects that is, effects whose direct cause is the language modality. In the alternative perspective where differences are due to other factors, such as the age of the languages in question, we may speak of indirect "modality effects" (in quotation marks), meaning that one would posit quasi-modality effects which look like they are due to the language modality but actually have other causes. This type of effect actually holds much interest for linguistic typology because of the implication that, in addition to modality-specific factors, there can be other drivers that constrain linguistic structures in similar ways

\footnotetext{
5 The availability of larger amounts of typological data on pidgin and creole languages is also a recent development, particularly since the publication of the Atlas of Pidgin and Creole Structures (Michaelis, Maurer, Haspelmath, \& Huber 2013).

${ }^{6}$ Note that while all sign languages so far are assumed to be 'young languages', there is very little documentary evidence of the actual age of individual sign languages, so one must be cautious about automatically including all sign languages here. Often, the official history of a sign language automatically begins with the establishment of the first schools for deaf children and is largely anecdotal. The oldest documentary evidence relates to the sign language used at the Ottoman court in present-day Turkey and goes back to the fifteenth century (Miles 2000), but it is not clear whether the modern Turkish Sign Language is a direct descendant.
} 
across both modalities. In other words, language modality may not always be the most decisive factor that trumps everything else in the patterns of cross-modal typological variation we find.

In both its variants, this second approach will appeal to typologists, as it must be a major endeavour in typology to capture the structures of human languages as comprehensively as possible, including across modalities. As sign language research has moved on from describing a few individual sign languages to documentation of a much wider range of diverse sign languages and subsequently to explicit typological studies on sign languages, this undertaking is now much more feasible and grounded in a broader data set. In the remainder of this article, we adopt the second approach, with an emphasis on the inductive nature of studying cross-modal patterns across languages of both modalities. In Section 3, the value of this approach is exemplified with respect to sensory perception metaphors, as the findings were entirely unforeseen at the beginning of the study.

Approaches to comparing signed and spoken languages

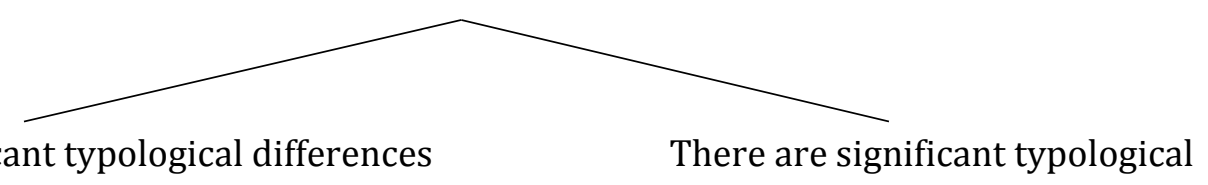

There are no significant typological differences differences

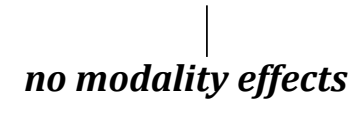

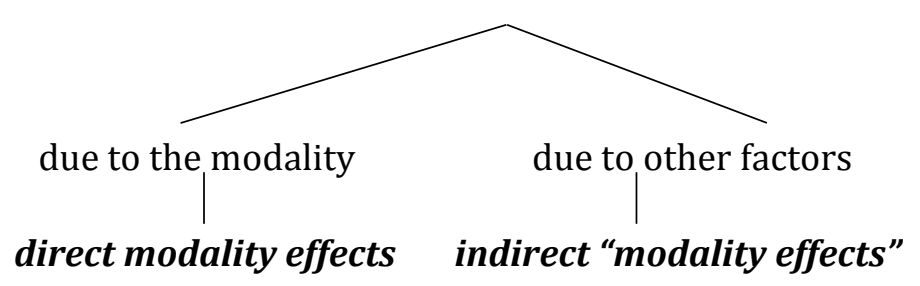

Figure 1. Approaches to comparability of signed and spoken languages.

Importantly, it is quite possible, and even likely, that comparing different grammatical-functional domains across signed and spoken languages would lead us to identify direct modality effects in some domains, quasi-effects or indirect "modality effects" in other domains, and no modality effects in yet other cases (Sections 2.2 and 2.3 discuss data from several grammatical-functional domains that illustrate this point). The immediate aim of cross-modal typology must therefore be to chart the territory of a wide range of grammatical-functional domains, and to look for evidence and arguments within each domain. Overall, we argue that the "direct modality effects" perspective, when applied carefully, seems to offer the best prospect of uncovering these patterns because it lends itself naturally to a strongly inductive way of working with primary data from a wide variety of languages in both modalities.

Given the perspective adopted here, the next task is to think about the kinds of modality effects that we may find in the data, and about their logical relationships with each other. The categorisations proposed in Section 2.2 are based on previous research over the past 15 years (see Zeshan \& Palfreyman 2017), and there are examples instantiating each type of modality effect. This is intended as a first-pass schema that allows us to cover the conceptual space of comparability between signed and spoken languages.

Section 2.3 then explains some of the analytical challenges associated with comparing signed and spoken language data, because there is much more involved in the task than simple categorisation. However, one of the most difficult issues needs to be raised upfront, and this is the question of what exactly we mean by the signed and spoken modality, and what exactly we are comparing.

As mentioned earlier in this section (e.g. with respect to composite utterances), it is increasingly being recognised that spoken languages are indeed not only auditory-vocal but multimodal. Most notably, this includes the use of co-speech gesture, and in the context of comparison between signed and spoken languages, the role of co-speech gesture becomes an obvious question. There are many correspondences between conventional hand gestures and manual signs, and many non-manual signals also have their origin in non-manual gestures and conventional facial expressions, which is why they tend to correlate 
with facial expressions used by hearing people in the same cultural area (cf. Zeshan 2004 on the backward head tilt for negation in Turkish Sign Language). Johnston (2018) has recently argued that the negative headshake in Australian Sign Language is 'gestural, interactive and prosodic in nature, rather than a discrete morpheme of negation', and that in most cases, its use is not fundamentally different from the corresponding head gesture used by hearing speakers of English. The question is therefore whether it is legitimate to compare sign language structures with spoken language structures without taking co-speech gestures into account.

Another related and perhaps even more important issue of comparability is not in relation to multimodality as such, but lies in the fact that sign languages are, for the most part, performance languages, that is, they are used in live face-to-face interaction. ${ }^{7}$ Therefore, it seems reasonable to posit that, in order to compare like with like, sign language data should be compared with spontaneously spoken discourse, and not with written text corpora. This increases the chances that co-speech gesture could come into the picture, especially if spoken language is captured on video, but without mandating that co-speech gesture always has to be included. From a pragmatic point of view, mandatory inclusion of co-speech gesture in all comparative data sets would result in the amount of available data being radically reduced, as there are few typologically useable reference materials on spoken languages that include co-speech gesture. ${ }^{8}$

\subsection{A typology of modality effects}

The basic, top-level distinction in our typology of modality effects is between relative modality effects and absolute modality effects. Relative modality effects occur where a certain cross-modally identified structure, while attested in both modalities, is markedly more frequent in one modality than the other. For instance, non-decimal numeral systems seem to be rarer in sign languages than in spoken languages. In Zeshan et al. (2013), the following examples of non-decimal numeral bases operating in various rural sign languages are discussed:

- $\quad$ additive base 50 in Alipur Sign Language, Mardin Sign Language, and Chican Sign Language

- $\quad$ additive base 20 in Chican Sign Language

- vigesimal sub-system in Mardin Sign Language (for numerals 20, 40, 60 and 80)

In addition, Báez-Montero \& Fernández-Soneira (2016) identified a vigesimal sub-system in the Galician variety of Spanish Sign Language (for numerals 20, 40, 60 and 80) in Zeshan \& Sagara (2016).

This currently very small number of instances compares with $21 \%$ of spoken languages identified as either pure vigesimal or hybrid vigesimal-decimal in Comrie (2013). Even if we allow for the strong possibility of further non-decimal numerals to be found in later research, given that so many sign languages are un- or under-documented, it seems unlikely that sign languages would match the pattern found in spoken languages. It is worth pointing out that non-decimal numeral (sub-)systems were identified in sign languages for the first time after over 40 years of sign language research; that is, the first several decades of sign language research did not uncover any non-decimal numerals.

Moreover, there is a viable conceptual explanation for the relative absence of numeral bases above 10 in terms of the embodiment of language, in this case, numerals being embodied within the 10 digits of the human hands. Even spoken languages often use source morphemes in their numeral systems whose meanings relate to the human hands, for instance with associations between 'hand' and 'five' (Majewicz 1984). With respect to numerals up to 10, sign languages in most cases simply use extended fingers for the numerals 1-5 and then fall into two groups (see Zeshan et al. 2013): either the numerals up to 10

\footnotetext{
${ }^{7}$ Like many spoken languages, sign languages do not have a long history of literacy. The SignWriting system uses visual symbols to represent the sublexical components of signs, and although it is not widespread in most countries, the system has an international community of users (see www.signwriting.org, accessed 2019-02-03). Another way in which sign languages transcend face-to-face use is via the production, sharing and publication of video recordings, and where the technical capabilities exist, signers increasingly use various channels for the dissemination of videos.

8 We acknowledge that this is not an analytically satisfying solution, but at least the issue can be kept in mind when readers want to interpret the examples in the next sections. The potential relevance of co-speech gesture is flagged up where applicable.
} 
have distinct forms, such as the handshapes in Ugandan Sign Language and Turkish Sign Language numerals for 6-9 shown in Figure 12 of Section 4, or the signs are made by extending the requisite number of digits (for example, five digits of one hand and two of the other hand meaning ' 7 '). In the latter case, such a system could be categorised as a 5-base system (with 10 consisting of 5+5). In any case, it can be argued that this embodiment may exert a much stronger pull in sign languages towards numerals that fall into one of the above patterns instead of numeral bases above 10, because the digits of the hands are immediately and directly present in a way that is not matched by spoken languages.

Relative modality effects can be weaker or stronger along a continuous scale. The above example is probably a rather weak modality effect, given that non-decimal numerals also occur with a relatively lower frequency across spoken languages, and the modality difference is merely that these numerals seem to be even rarer in sign languages. A stronger modality effect is found in the domain of negation, specifically with respect to morphological negation expressed by an affix on the verb, as in example (1) with a negative suffix from Turkish, and example (2) with a negative prefix from Persian:

$$
\begin{aligned}
& \text { et-me-mek } \\
& \text { do-NEG-INF } \\
& \text { 'not to do' } \\
& \text { ne-mi-kon-am } \\
& \text { NEG-PRS.PROG-do-1Sg } \\
& \text { 'I am not doing (it).' }
\end{aligned}
$$

This type of negation is widespread across spoken languages - 395 out of 1,157 languages in Dryer's (2013) sample mark negation by affixing. In sign languages, negative affixes are rare. In the majority of documented cases, negative affixes in sign languages occur as suffixes, and prefixes seem to be rare; however, there are instances of negative prefixing in Polish Sign Language (Tomaszewski 2015), and negative proclitics occur in Indonesian Sign Language (Palfreyman 2019). In addition to being crosslinguistically less frequent, where negative affixes do occur in sign languages, they are subject to lexical and formational constraints, often limited to only a few lexical items, in particular high-frequency verbs, as in Finnish Sign Language (Zeshan 2004; see Figure 2) and in Ugandan Sign Language (Lutalo-Kiingi 2014). ${ }^{9}$ By contrast, negative affixing in spoken languages, including the Turkish and Arabic example above, works across the board and applies to most or all verbs.
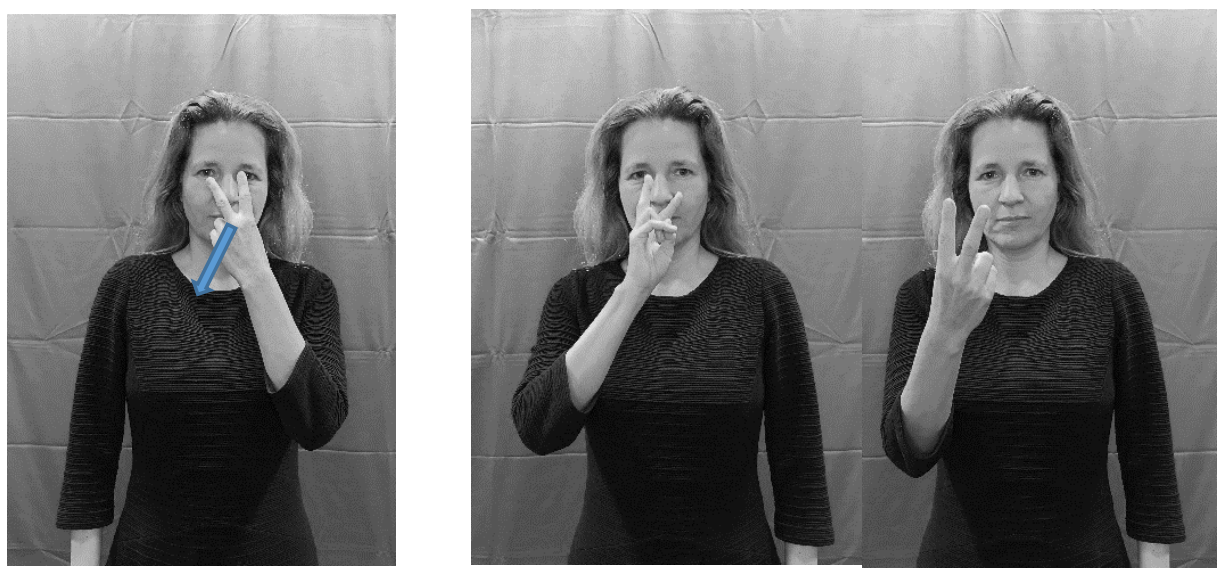

Figure 2. An example of negative affixing in Finnish Sign Language with the sign SEE (from Zeshan 2004) - the twisting motion away from the body with the change in hand orientation constitutes the negative affix in the right-hand sign.

In sign languages, the preferred negation strategies are negative particles and non-manual negation via head movements, including headshake, that are superimposed on the manual signs. ${ }^{10}$ Non-manual

\footnotetext{
9 There are also examples of negative suppletion across sign languages. Like negative affixing, negative suppletion is also limited to relatively few high-frequency lexical items (Zeshan 2004: 43; Palfreyman 2019). ${ }^{10}$ Studies by Zeshan $(2004,2006)$ on manual and non-manual negation were necessarily based on limited datasets, and detailed work on Auslan (Johnston 2018) and Kata Kolok (Lutzenberger 2018) has recently reassessed the
} 
markers that co-occur with manual signs to signal grammatical functions such as clause types, including negation, are commonly considered to be suprasegmental, although recent work by Pfau (2008) argues for an analysis of negative headshake as a featural affix that triggers a prosodic change in the form of the headshake.

Considering these three main types of negation - particles, morphological negation, and suprasegmental negation - the available data suggest the following:

- No modality effect with respect to negative particles; they are common in both signed and spoken languages.

- A strong relative modality effect with respect to morphological negation, which is well-attested in spoken languages but more marginal in several ways in sign languages. This could be viewed either as a direct modality effect, if we argue that the pattern is due to the modality itself, or an indirect modality effect, if we consider that the paucity of morphological negation has something to do with the young age of sign languages. The latter view is in line with morphological negation taking time to evolve, and the existing cases tending to be high-frequency items.

- Either an absolute modality effect, or a very strong relative modality effect with respect to suprasegmental negation (provided one adopts the view of negative headshakes as suprasegmental). This is very frequent in sign languages, but absent from or very rare in spoken languages. ${ }^{11}$

Unlike in the case of decimal and non-decimal numerals, it is difficult to posit a cognitive reason for these patterns. Rather, these patterns may have to do with general preferences and dispreferences of sign language structures, namely the preference for simultaneous rather than sequential morphology, and the possibility of layering non-manual markers on top of manual signs. In addition, the preference for head movements also has to do with the fact that the same head movements are used as non-manual gestures by hearing people, and these are carried over into sign languages.

The second main type in our typology is the absolute modality effect. Absolute modality effects involve structures that are only attested in one of the two language modalities in question, and absent from the other. This category is subdivided into two sub-types. Firstly, a certain phenomenon or structure could simply be unattested in one of the modalities. One example is the fact that numerals including the morphemes 'and' or 'with', as in examples (3) and (4) from German and Arabic, have not been found in any sign languages (Zeshan et al 2013).

$$
\begin{aligned}
& \text { drei-und-zwanzig } \\
& \text { three-and-twenty } \\
& \text { ' } 23 \text { ' }
\end{aligned}
$$

$$
\begin{aligned}
& \text { thalatha-wa-ishreen } \\
& \text { three-and-twenty } \\
& \text { ' } 23 \text { ' }
\end{aligned}
$$

In this case, an example of the structure in question, that is, a sign language numeral with an 'and'- or 'with'-morpheme, could conceivably be found but is not currently within the domain of available data. In fact, 'unattested' in this sense may be read as 'currently unattested' or 'not yet attested'. It is intrinsic to typology in general that phenomena in question can move from the 'absolute' to the 'relative'

\footnotetext{
role of manual and non-manual negation in those languages. It is to be hoped that further studies of these and other languages will continue to enrich our cross-linguistic understanding of negation in sign languages.

11 An example of a negative intonation contour, which may be akin to non-manual suprasegmentals in sign languages, has been reported in Kuot (Lindström 2002). However, in order to be parallel with what happens in many sign languages, this negative intonation would have to be sufficient as the only marker of negation, without any co-occurring segmental material also marking the negation, and this is not the case.
} 
categories, as soon as at least one example of the putative structure is found. ${ }^{12}$ Successive movements from one modality effect category to another are discussed further below in this section.

The second type of absolute modality effect is qualitatively different and refers to structures that are ruled out a priori in one of the modalities. An example of this is the spatially distributive aspect that is found in the majority of sign languages. As shown in example (4) and figure (3), this aspect is a particular type of reduplication, where the predicate is reduplicated at several different locations in the threedimensional signing space.

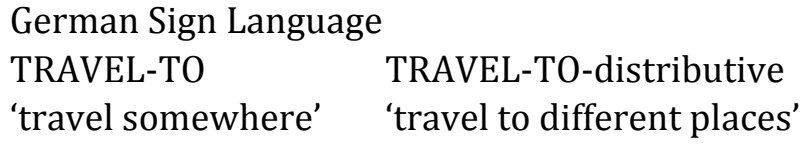



3.1 TRAVEL-TO

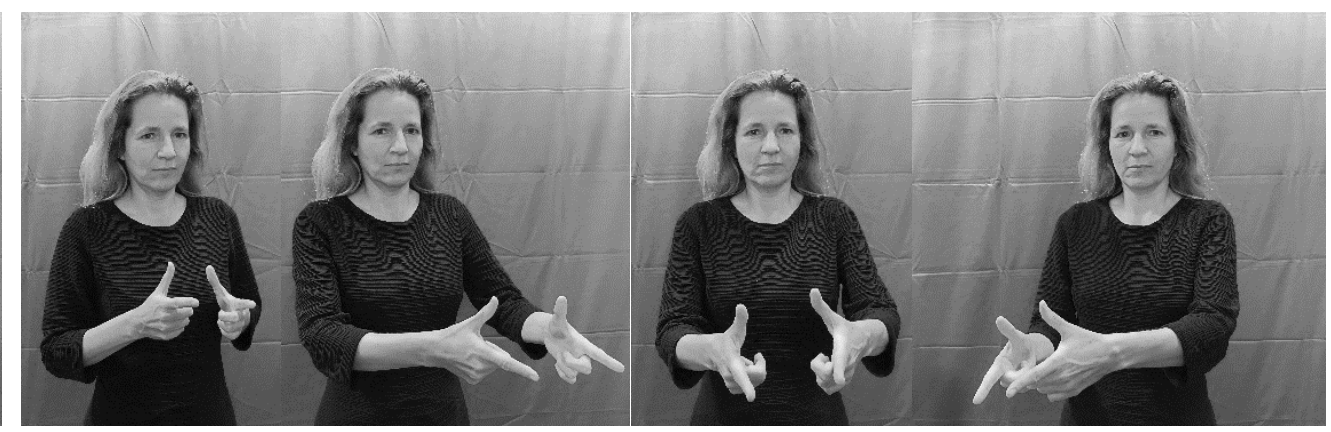

3.2 TRAVEL-TO-distributive

Figure 3. TRAVEL-TO in German Sign Language: citation form (with single forward movement) in 3.1 and distributive aspect in 3.2 (which uses a sequence of photos indicating how the sign is articulated).

Since this morphological process relies on the availability of a three-dimensional space, it can be argued that this structure is a priori not available to the auditory-vocal modality. Of course, various spoken languages do have verbal morphology with an equivalent distributive meaning, and this may or may not be realised by reduplication of some morphological material. However, this is not closely similar to the distributive aspect in sign languages. For example, sign language structures such as that in (4) allow for further iconically motivated mapping between the form and the meaning of the signs depending on the meaning to be conveyed, including the following:

- the end points of the movement can be higher or lower in the 3D space

- the end points of the movement can be closer together or further away from each other. This may convey either the real-world physical locations, or abstract relationships, e.g. with locations on opposite sides of the signing space being in a logical contrast with each other

- the movement can be shorter or longer, i.e. ending closer to or further away from the signer's body

- the movement can be one-handed or two-handed (in some sign languages)

The vocal productions of spoken languages have no equivalent mapping of form and meaning with such movement predicates, although similar structures occur in co-speech gesture. Some of the features in the above list also share with co-speech gesture the fact that they are gradient. The exact shape and end point of the movement correspond to the meaning via iconic mapping; for example, the longer the movement of the sign, the longer is the distance conveyed by the sign. The fact that signs include both categorical and gradient elements, or, as argued in Liddell (2003), both linguistic and gestural elements, is an effect of the visual-gestural modality and the potential for visual iconicity. The issue of phonememorpheme distinction is related to this point (see Section 2.3).

Unless we consider multimodality in spoken language productions to be a mandatory part of the comparison, the distributive aspect is an absolute modality effect where the occurrence in one modality

\footnotetext{
${ }^{12}$ In parallel with this observation is the tendency in linguistic typology for putative universals to be 'downgraded' over time to statistical tendencies.
} 
is ruled out a priori. Another example of an absolute modality effect in the same category is the existence of single-stage perceptual metaphors described in Section 3. This phenomenon is due to the widespread availability of sub-lexical iconicity in sign languages in this semantic domain, which is, to our knowledge, not found in spoken languages. As we will see in Section 2.3, the arguments as to what can fall within the 'a priori ruled out' type of modality effect are not always clear-cut and can present considerable analytical problems.

The different kinds of modality effects described in this section can be summarised as in Figure 4 . Modality-independent variables are those that occur with equal likelihood in signed and spoken languages, so that an effect of the modality on the structure is not in evidence. The progress bar under the relative modality effects represents the continuum of modality effect strength.

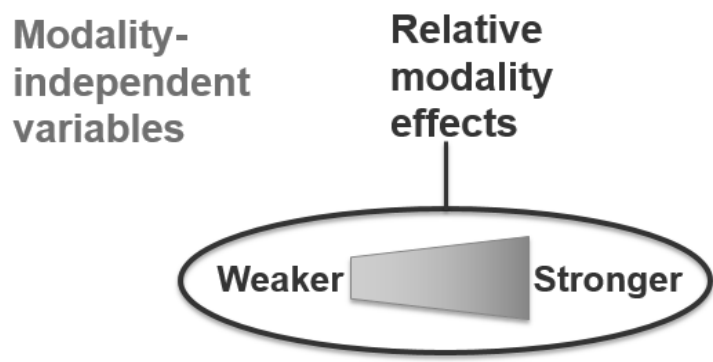

Figure 4. Types of modality effects.



Across these different types of effects, an analytical task is to distinguish between weaker and stronger relative effects, as well as the boundaries between strong relative and absolute modality effects on the one hand, and weak relative modality effects and modality-independent variables on the other hand. How much of a shift in the balance between occurring structures is enough to decide that candidate categorisations should be re-assigned?

With respect to weaker and stronger relative modality effects, it is obvious that this is a matter of degree and ultimately of individual argument. However, it is also worth pointing out that there is a natural direction of 'movement' from one type to another, as the amount and diversity of sign language documentation increases: spoken language typology is several decades ahead of sign language typology, and the changing data basis concerns sign languages much more than spoken ones.

The non-occurrence of numerals with 'and'- or 'with'-morphemes in sign languages has been posited as an absolute modality effect above. However, there is of course the potential for examples of this structure to become known as more and more sign languages are documented in detail. As soon as one or two such examples are found, the modality effect would move from the 'absolute' type to the 'relative - strong effect' type. Finding even more examples would then weaken the relative modality effect, and push the categorisation further down the line, towards the 'relative - weak effect' end of the continuum. It is even conceivable that eventually, the modality effect may have to be discounted altogether, and the data would ultimately show no modality effect any more, moving this variable to the 'modalityindependent' category. This natural progression within the proposed typology is shown in Figure 5, with the arrows from right to left.

The opposite movement is also possible, though perhaps less likely. For instance, with respect to possessive constructions, it seems that both signed and spoken languages make ample use of the grammaticalisation path from 'holding/grasping' to 'having' (see Heine 1997 on this grammaticalisation). However, if future research on a larger number of sign languages was to show no further evidence of this source construction for possession, and it turned out that the examples found so far in sign language had been quite exceptional, the 'holding/grasping-for-having' construction could move from being a modality-independent variable to being a relative modality effect, initially a weaker one, and with increasing negative evidence, eventually a stronger one (see the arrows from left to right in Figure 5). 
However, additional data would not normally generate any movement from a relative to an absolute modality effect because a relative modality effect is already defined as having occurrences in both modalities. The only way that one could move to an absolute modality effect would be by way of redefinition of the analytical issue, so that a signed and a spoken construction that were considered comparable are re-defined as in fact not being in parallel with each other. Finally, absolute modality effects of the kind where a variable is a priori ruled out from occurring in one of the modalities will not show any such movement effects. Again, the only way in which such a modality effect could be reassigned to another category is if there is an analytical or definitional shift compared to the initial analysis of the data. The challenges raised by such analytical and definitional shifts are discussed in more detail in Section 2.3.



Figure 5: Movement paths between types of modality.

\subsection{Analytical challenges in cross-modal typological comparisons}

Analytical challenges in the interpretation of cross-modal typological data differ depending on which type of modality effect we are dealing with. The issue of re-adjusting the categorisation of modality effects, in particular with respect to weaker and stronger relative effects, has been discussed in the previous section. This is as much a methodological as an analytical issue because the re-assignment between types of modality effects is closely related to current deficiencies in the available data base in sign languages. For example, if our data quality threshold for sign languages requires that we only include data that are underpinned by a substantial digital corpus, this will constrain analysis and will suggest quite different generalisations than a much larger range of data, which is however also much more unreliable. Early work in Sign Language Typology, e.g. Zeshan (2006), has addressed such issues, and with respect to relative modality effects, this is no different in cross-modal typology.

However, the issue of comparability between modalities poses itself much more forcefully in the case of absolute modality effects, in particular with respect to the question of what counts as comparable in cross-modal typology. There are two levels to the issue of comparing like with like in cross-modal comparison. The first is the level of the language modality as such, as argued in Section 2.1 with respect to the issues around multimodality. The second is the level of individual modality effects. In order to argue for the presence of an absolute modality effect, one must make sure that the right standard of comparison is chosen.

Let us first consider an example of an absolute modality effect that may be due to a structure that is a priori ruled out in one modality. In Alipur Sign Language from southern India, the numerals 100, 1,000, and 100,000 are formed by making a successively larger movement in three-dimensional space, while the other aspects of sign formation remain the same (see Figure 6, from Zeshan et al. 2013). We might argue that such a spatially expressed morphology a priori has no equivalent in spoken languages, since they do not exist in three-dimensional space, and that we automatically identify an absolute modality effect. 


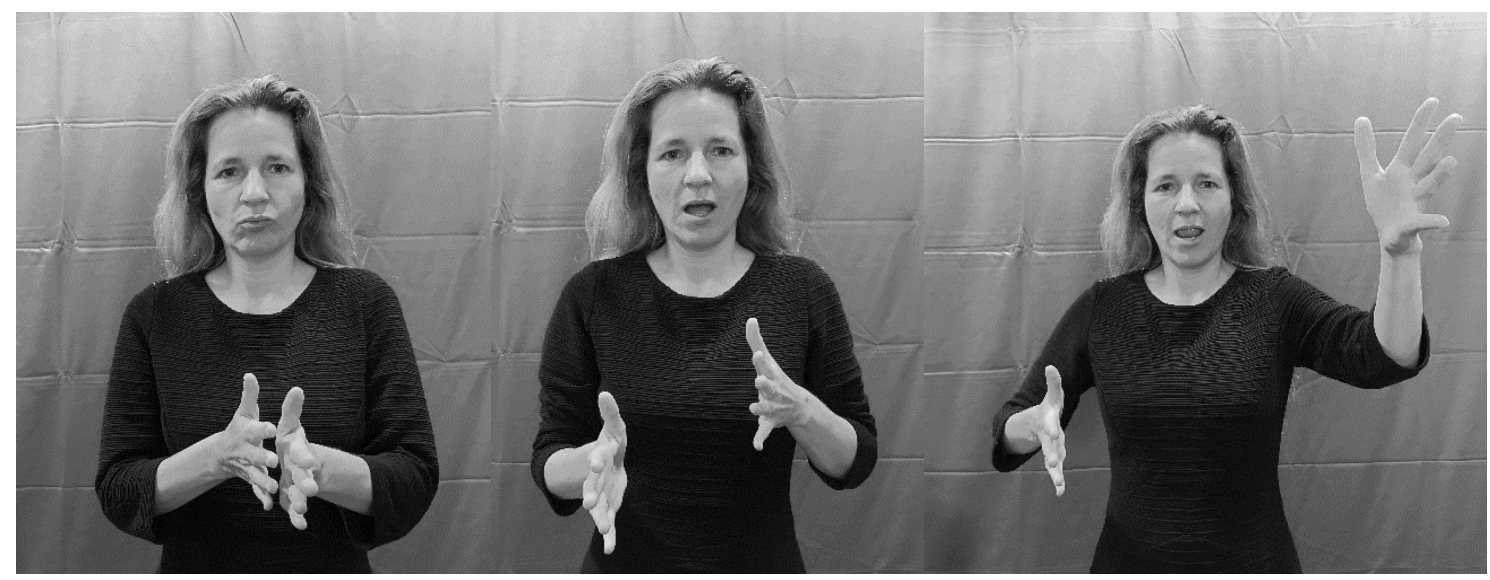

Figure 6. Numerals 100, 1,000 and 100,000 in Alipur Sign Language (all signs have alternating circular movements).

However, it is also possible to argue that instead of positing this type of modality effect, we should try to look for the closest possible comparable phenomenon in the spoken modality that would correspond to enlarged space in the signed modality. In order to do this, some analytical considerations will be necessary. In Brentari (2002), it is argued that at the phonological level, the movement parameter in sign languages is equivalent to vowels in spoken languages (the hand configuration being equivalent to consonants). This is because movements have more perceptual amplitude than other aspects of the sign, just like vowels are at the core of syllabic structure in spoken languages. Given this reasoning, we could imagine a putative Language $X$ with hypothetical data as in example (6) - the number of vowel letters represents vowel length.

(6a) bat

' 100 '

(6b) baat

' 1,000 '

(6c) baaat

' 10,000 '

In (6), increasing vowel length corresponds to the larger numerals, just like increasing amplitude of the movement does in Alipur Sign Language. If we accept this as a closest possible equivalent to what happens in Alipur Sign Language, the absolute modality effect is no longer in the 'a priori' category but in the category where something is unattested in one modality. It is now a matter of empirical evidence whether an absolute modality effect can be verified or not. This is logically and analytically quite a different outcome and therefore of some importance.

In this example of 'physical amplitude-to-numeral' mapping, we may try to abstract away from the physical form of sound-based words and visual-gestural signs, but this is not always legitimate. The conditions under which comparability can be successfully argued for despite major differences in the phonological/sub-lexical systems of spoken and sign languages are currently not well understood, as linguistic typology has not properly caught up with such comparisons.

Another issue of comparability that has to do with the phonological level is the degree to which sign languages have a higher degree of 'iconicity', i.e. non-arbitrary relationships between the form and the meaning of signs. The earliest research by Stokoe (1960) found that signs are formed of 'parameters' at the phonological level, sub-lexical elements which, it was claimed, correspond to phonemes in spoken languages. These parameters are handshape and hand orientation, place of articulation, movement, and non-manual features (including elements such as head movement, mouth patterns and eyebrow movement). A difference in a single parameter leads to a different sign that may have a very different meaning, and two such signs constitute a minimal pair. Unlike spoken language phonemes, these parameters mostly occur simultaneously, rather than sequentially (Brentari 1998, Wilbur 2000, Sandler 2012). In addition, non-manual elements can occur suprasegmentally, which - along with two manual 
articulators that may operate independently of each other - creates further scope for simultaneity in the realization of grammatical functions. ${ }^{13}$

The original notion that these parameters correspond to the meaningless sub-morphemic elements of spoken languages has increasingly been regarded as problematic, in large part because sign languages often exploit iconicity. 'Iconicity' is itself a complex concept with a substantial number of sub-types (Zucchi 2018), but for this article we refer to iconicity in terms of any non-arbitrary relationship between the form of a sign and its meaning. There are many ways in which signs can be iconic. For example, signs can look like what they mean, e.g. a sign for 'book' with two open hands touching along the sides, as if shaping the pages of an open book (this could also be said of onomatopoeia and ideophones in spoken languages, e.g. Dingemanse et al. 2015, Haiman 2017). More abstract iconicity in grammatical systems is also pervasive in sign languages, and the above example of the distributive aspect falls into this category. ${ }^{14}$

At the sublexical level, such iconicity renders the phoneme-morpheme distinction ambiguous for sign languages. Some linguists have posited that the phoneme-morpheme distinction does not apply to sign languages in the same way as to spoken languages (e.g. Cuxac 2000), or have addressed such issues in the context of the notion of lexemes (e.g. Johnston \& Schembri 1999, Johnston \& Ferrara 2012). Zeshan (2002) argues that the traditional distinction between phonemes and morphemes should be modified for sign languages to allow for meaningful elements at the phonological level. For spoken languages, the impact of phonaesthemes on the phoneme-morpheme distinction has been explored in detail in Kwon \& Round (2015), and there are interesting parallel arguments (see also Section 3.3).

This fundamental design feature of sign languages plays a prominent role in the analysis of sensory perception metaphors in Section 3. Again, if a specific type of iconic mapping is, at first sight, not found in spoken languages, should one posit an 'a priori ruled out' case, or try and look for the closest possible comparability? In the latter case, how close is close enough to be acceptable? In the case of sensory perception metaphors, there seem to be no candidate structures that could count as comparable, but in other cases, there may be much room for debate.

As the field of cross-modal typology develops, it seems sensible to posit that categorisations of modality effects are provisional and can move from one category to another as the data base and the analytical views on comparability evolve. Rather than a fixed system of once-and-for-all categorisation, it is more useful to view modality effects as a flexible design space, within which the different comparable crossmodal structures are temporarily situated. Further, it is legitimate to argue that, when engaging in crossmodal typology, similarity and comparability across the modalities will be a matter of judgement to some extent.

It is however vital to make these judgements within a principled framework and to make explicit any underlying assumptions. A principled framework may include factors such as knowing the various categorisations between which one has some leeway to make judgements; understanding the implications of making a choice either way, for example in terms of moving from one categorisation of modality effect to another; keeping the internal logical consistency of linguistic argumentation intact; and keeping a holistic, comprehensive view of the language data in mind when making judgements about comparability.

We seek to give an example of such a framework as we turn to another domain, to see what kinds of effects occur for metaphors of sensory perception.

\section{Sensory perception metaphors}

The discussion here of perceptual metaphors draws on a convenience sample of data from 24 sign languages (further details of the research method are provided in Zeshan \& Palfreyman 2019, including some caveats about the nature of the data that are included). Our starting point was the observation that, for sign languages, the semantics of sensory perception is evident, in the vast majority of cases,

\footnotetext{
13 Though, of course, suprasegmentals do occur in spoken languages, from tone and voice quality up to intonation.

${ }^{14}$ Haiman (1985) argues that some features of spoken language grammar may also exhibit iconicity.
} 
from the form of the sign: we refer to this as the Transparency Principle of Sensory Perception in sign languages. For example, signs linked to hearing are located at/near the ears; signs linked to taste are articulated by the lips, tongue or near the mouth, and so on. Such signs may make contact with a body part - such as the nose, for signs linked to smelling - or may feature a proximal or distal movement (for example to or from the eyes, in the case of 'seeing'). Signs that reference 'feeling', in the haptic sense, are often located on the chest, cross-linguistically, but other places of articulation also occur (such as the back of the hand for the British SL sign meaning 'sensitive').

The Transparency Principle of Sensory Perception involves an iconic mapping between a sign's meaning and its form, in this case at the level of sub-morphemic components, as the place of articulation of signs is one of the formational parameters of signs and operates at the phonological level. The fact that signs 'look like what they mean' has major implications for this and other domains. When considering signs that express metaphors deriving from sensory perception, two types emerge from our analysis, and neither of these occurs for spoken languages in quite the same way. We refer to these as 'single-stage' and 'double-stage' sensory perception metaphors: for ease of explanation, these are introduced in reverse order.

\subsection{Double-stage sensory perception metaphors}

Double-stage metaphors have similarities with the kind of metaphorical semantic changes reported to occur for spoken languages (e.g. Speed et al. 2019). In these cases, one and the same sign has a concrete sensory meaning and a metaphorical one, and both meanings are available in the same language. Mappings between seeing-understanding and hearing-knowing are attested in several spoken languages (Sweetser 1990, Alm-Arvius 1993, Evans \& Wilkins 2000) and examples for sign languages are shown in Table 1 . The semantics for sign languages initially features sub-lexical iconicity (the place of articulation) along with an additional shift from literal to metaphorical meaning (hence the description of this phenomenon as 'double-stage').

Table 1. Examples of double-stage metaphors in sign languages.

\begin{tabular}{lll} 
literal / metaphorical meaning & languages in which these signs occur & location of sign \\
\hline 'blind' / 'not want to know about' & Chinese SL, South Korean SL & eye \\
\hline 'wink' / 'secret understanding' & Indian SL & eye \\
\hline 'look' / 'let's see about that' & Turkish SL & eye \\
\hline 'broken eye' / 'careless' & Indonesian SL & eye \\
\hline 'pepper' / 'talk angrily' & Turkish SL & mouth
\end{tabular}

Most of the examples in Table 1 are linked to 'seeing', and it is perhaps unsurprising that this kind of sensory metaphor is common across languages used by deaf signers, who have been referred to as 'visual people' (Bottari et al. 2011). However, visual perception is common too as a source of metaphors in spoken languages, and it is not clear whether this pattern is linked to the fact that most signers perceive sign languages visually. Besides, perceptual metaphors based on other senses can also be found, such as 'talk angrily' in Turkish SL, which has undergone several semantic shifts from 'spicy taste' to 'pepper' to 'talk angrily' (the latter has a more vigorous movement and an added tongue waggle).

\subsection{Single-stage metaphors of sensory perception}

The single-stage sensory perception metaphors for sign languages do not occur in spoken languages because the metaphor, while associated with sensory perception, only has lexical meaning as a metaphor: while the double-stage signs had a metaphorical meaning derived from a literal meaning, for the single-stage signs, this initial stage of concrete sensory meaning is missing. In other words, the lexical meaning of sense perception from which a lexical meaning with metaphorical extension would normally be derived is absent for this type of sign.

For an illuminating example, consider the sign meaning 'not want to know about' something, mentioned in Table 1 and illustrated in Figure 7. 




Figure 7. The sign meaning 'not want to know about' something.

This sign functions differently in different languages and occurs in four of the sign languages included in our sample: Chinese Sign Language (northern China), South Korean Sign Language, Indian Sign Language and Indonesian Sign Language. For the first two sign languages, it is also a lexical sign with the literal meaning 'blind', and hence in those languages it is a double-stage metaphor - its origins can be traced to this literal meaning. The metaphorical extension is based on a connection between seeing and knowing that is well-documented for spoken languages (see for example Lakoff \& Johnson 2003). However, an added volitional sense is apparent - if one who is not blind places one's hand over one's eyes, it indicates that one does not wish to see something, and by association does not want to know about something. For both meanings, the sign is formally identical, but the volitional sense is evident when the sign refers to one who is not blind, and who therefore does not wish to see or know.

For Indian SL and Indonesian SL, however, the sign only has the volitional sense, and does not mean 'blind'. In fact, both Indian SL and Indonesian SL use other, formationally-unrelated signs meaning 'blind' (shown in Figure 8), and the sign in Figure 7 does not have a lexical meaning linked to sense perception.
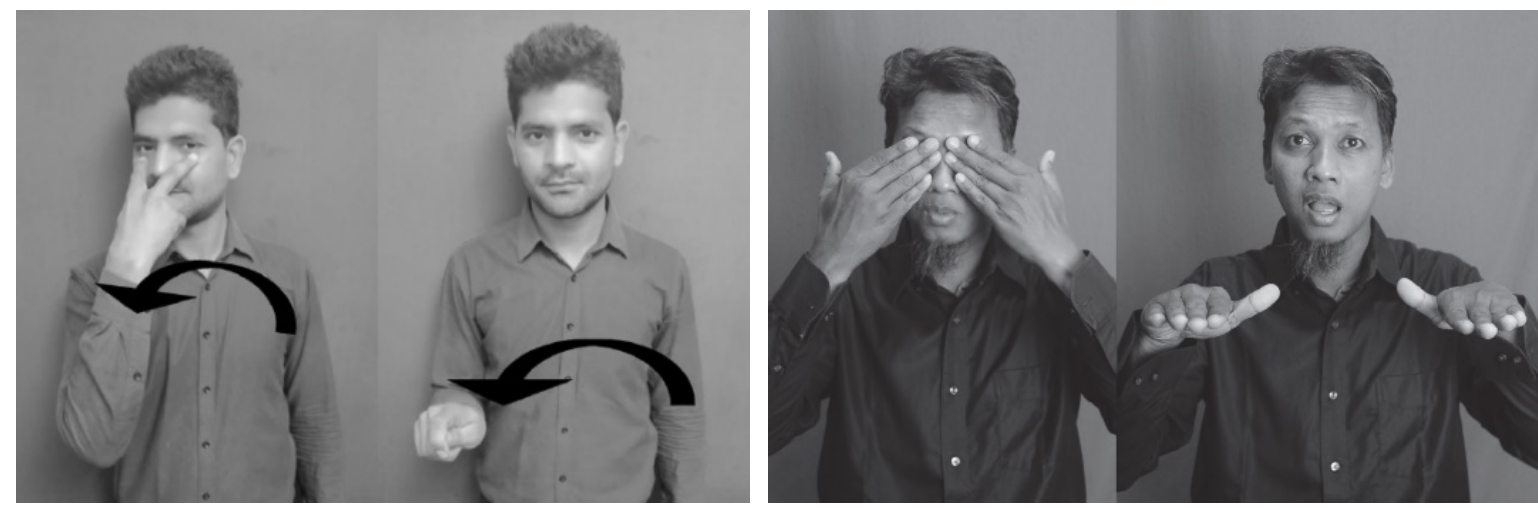

Figure 8. Signs meaning 'blind' in Indian SL (left) and Indonesian SL (right).

Because of this, the sign is classed as a single-stage metaphor in Indian SL and Indonesian SL. This and other examples of single-stage metaphors are shown in Table 2, and two examples are shown in Figure 9. The first of these, 'news', involves a listening gesture with the hand cupped behind the ear, while the latter, 'greedy', is based on 'making big eyes' for something.

Table 2. Examples of single-stage metaphors in sign languages.

\begin{tabular}{lll} 
metaphorical meaning & languages in which these signs occur & location of sign \\
\hline 'not want to know about' & Indian SL, Indonesian SL & eye \\
\hline 'not want to hear something' & Indonesian SL & ear \\
\hline 'news' & Indian SL, Chinese SL, Polish SL & ear \\
\hline 'no information' & South Korean SL & ear \\
\hline 'greedy' & Brazilian SL & eye
\end{tabular}





Figure 9. Signs meaning 'news' (in Indian SL, Chinese SL and Polish SL) and 'greedy' (in Brazilian SL).

Deaf signers do not take in information by hearing, and with that in mind it may be surprising to find signs with meanings linked to absorbing information that are based on the auditory sense - one might have expected that these signs would draw upon the visual sense, and of course, such signs do exist. However, metaphorical signs based on an association between hearing and knowing are frequently attested cross-linguistically. We discuss this matter further in Zeshan \& Palfreyman (2019).

\subsection{Signed perceptual metaphors and modality effects}

The reason single-stage metaphors are available even without literal meanings of sense perception is the Transparency Principle mentioned at the beginning of Section 3: the sense perception is triggered by the use of a place of articulation located at the sense organs. Key to this is the fact that the place of articulation is itself a sub-lexical component; meaning is available to sub-lexical components because of their iconicity. As argued in Section 2.3, the availability to sub-lexical components of meaning through iconicity without their having morphemic status is typical of sign languages.

The equivalents in spoken languages have been referred to as 'phonaesthemes' (Firth 1930; Kwon \& Round 2015; Benczes 2019: 63; Blust 2003) -sound-symbolic components of words such as [sl] in slime, slop, sludge and slush, where the sound in the word mimics in some way a quality of a referent. Kwon \& Round (2015) discuss in detail the characteristics of these components and what makes them distinct from morphemes, notably the fact that words with phonaesthemes can usually not be exhaustively divided up into meaningful components. That is, 'sl' in 'sludge' is meaningful but the non-recurrent residue 'udge' is not.

Interestingly, the signs discussed in this section have the same structure, that is, they consist of iconic components and residues. However, this type of iconicity is much more prevalent in sign languages, making it a good candidate for a relative modality effect. In fact, in several of the above examples, there is more than one meaningful parameter. For instance, the Brazilian Sign Language sign GREEDY, not only is the place of articulation meaningful in terms of the sensory perception metaphor, but the handshape is also meaningful, representing a large size delimited by the thumb and the index finger. It is possible for signs to be completely decomposable into sub-morphological meaningful units. For instance, in a cross-linguistically common sign for 'book' (see Section 2.3), all parameters are iconically motivated, with the handshapes mapped onto the form of the book, the movement imitating the opening of the pages, and the place of articulation in front of the signer where the imaginary book is held. By contrast, Kwon \& Round (2015) hardly mention any such cases, and the most common occurrences of phonaesthemes involved only one meaningful phonological component.

The decision to regard single-stage signs as the result of metaphorical transfer can sometimes depend on whether one feels that sense perception is triggered by virtue of the place of articulation or not. For example, the sign SEEM in British SL, shown in Figure 10, is articulated from the nose and away from the face. As we have noted elsewhere, 'it is a matter of interpretation whether this is regarded as a metaphorical extension from smell to intuition, or whether one regards the [place of articulation] as an arbitrary sub-lexical component of the sign' (Zeshan and Palfreyman 2019: 289). 




Figure 10. SEEM in British SL.

Double-stage and single-stage metaphors are represented schematically in Figure 11. Both types use meaningful sub-lexical components that draw on iconic mapping between place of articulation and the associated sense of perception. For double-stage metaphors, the first step is from sub-lexical iconicity (SLI) to a sign with initial lexical semantics (LS1) that are located in the source domain semantics of sensory perception in a literal sense, with a subsequent step involving a transfer to the secondary lexical semantics (LS2) of the target domain. For example, on the left-hand side of Figure 11, the eye location is an instance of sub-lexical iconicity, and a sign meaning 'blind' (the source domain semantics LS1) also means 'not want to know about' (the target domain semantics LS2). The label SLI $\rightarrow$ LS1 $\rightarrow$ LS2 indicates that two separate lexical semantics are at play. Conversely, for single-stage metaphors there is no lexical meaning of sensory perception at all. For instance, the South Korean sign NO-INFORMATION uses the ear location for sub-lexical iconicity but the sign has no meaning associated with the source semantics of 'hearing' and refers to the target domain of cognition only. Therefore in Figure 11 we use the label SLI $\rightarrow$ LS2 to indicate that the literal lexical meaning LS1 is absent.

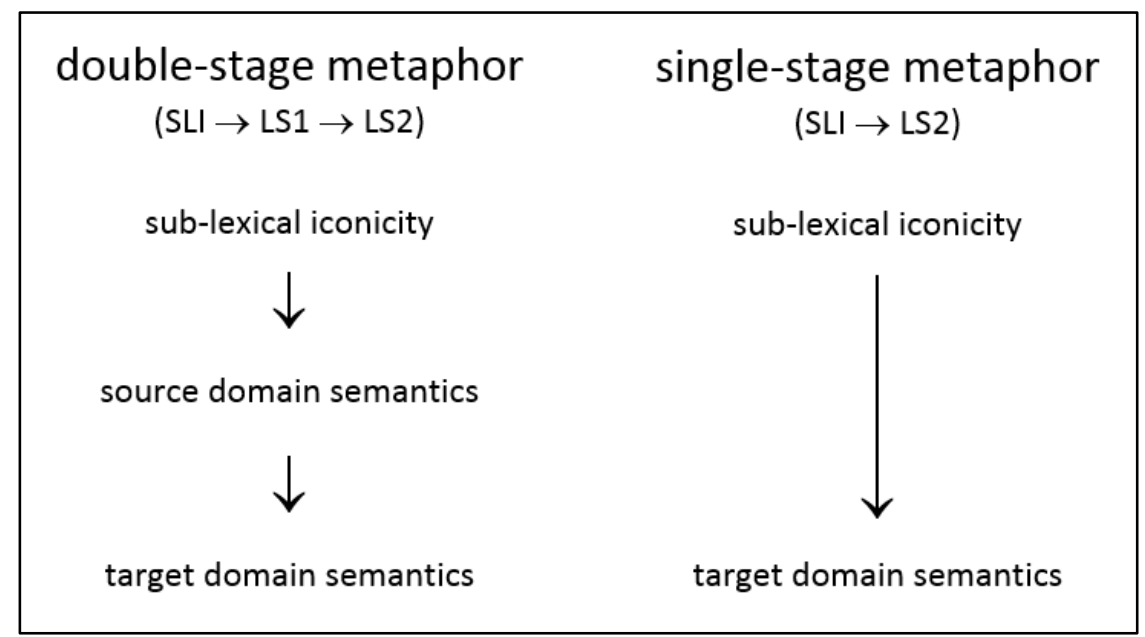

Figure 11. A schematic representation of double- and single-stage perceptual metaphors in sign languages.

To return to our theme of modality effects, single-stage perceptual metaphors are classed as an absolute modality effect because spoken languages do not use meaningful sub-lexical components that draw on anything akin to the Transparency Principle of Sensory Perception for sign languages. The phenomenon of phonaesthemes, though akin to iconically motivated parameters in signs, is not parallel to single-stage perceptual metaphors because no metaphor or target domain is involved. Instead, phonaesthemes, to the extent that they are iconically motivated, have the form SLI $\rightarrow$ LS1, for example English clang (LS1) being based on the iconicity of the final nasal sound (SLI). No metaphor is involved, that is, formmeaning pairings are based on sub-lexical iconicity but there is only a single meaning and no further semantic extension to a target domain.

As far as double-stage metaphors are concerned, their classification depends on the importance we assign to sub-lexical iconicity. If sub-lexical iconicity is an important and indispensable aspect, then 
double-stage metaphors are also part of absolute modality effects. This would allow us to generalise over both types of metaphors when focusing on the specific way in which both of the types in sign languages are different from all spoken languages. On the other hand, if we argue that the main focus in investigating metaphors should be on semantics, we might choose to disregard sub-lexical iconicity in the case of double-stage metaphors, which then makes them look more parallel to spoken languages. This would also imply that we prioritise highlighting the substantial parallels at the semantic level that exist with respect to source and target domains in sensory perception metaphors across both modalities. Again, this argumentation shows the important role of analytical judgements when making decisions on the classification of modality effects.

As we mentioned earlier, the findings on sensory perception metaphors were entirely unforeseen at the beginning of our study, and this merely underlines the importance of taking an inductive approach that is open regarding the status and theoretical significance of the findings that emerge.

\section{Conclusions}

In the newly emerging field of cross-modal typology, researchers face challenges both in terms of the constantly shifting data base and in terms of analytical conundrums. While the former can be addressed gradually over time, the latter is a challenge that we can immediately engage with. In this article, we have sought to do this, focusing on various categories, types, and lines of argumentation with respect to comparability between signed and spoken languages. In this concluding section, we summarise the most pertinent issues and indicate where future lines of investigation could be focused.

With the exception of syntax, the examples and issues discussed in this article have covered all levels of linguistic organisation. At the phonological level, the question of the phoneme-morpheme distinction in signs and words whose sub-lexical components are (fully or partly) iconically motivated has been pertinent to the discussion of sensory perception metaphors. Various morphological domains, such as aspect, morphological negation, and complex numerals, have featured in the examples of different modality effects. And the role that multimodality, in particular co-speech gesture, plays in composite utterances, extends up to the level of discourse. In future research, it would be desirable to go beyond the more obvious candidate structures for modality effects, which have predominantly been at the morphological level. In particular, it seems that the phonological level has the potential for some profound conclusions about the influence of modality on structure.

In considering these various examples, one of the pervasive issues has been the fact that shifting our choices of how to do cross-modal comparisons changes the outcome of these comparisons. When discussing modality effects, it is often not enough to merely describe the realisation of a phenomenon across signed and spoken languages. In many cases, analytical choices have to be made in order to arrive at an interpretation of these data.

For example, the fact that all known sign languages use pointing in space for personal pronouns is a reasonable candidate for an absolute modality effect (as well as for a substantive language universal among sign languages). However, this omits the probable parallelism between pronominal pointing in sign languages and co-speech pointing gestures in spoken languages. If we readjust the definition of what we mean by the spoken modality, it becomes possible to argue that in spoken languages we must take account of entire multimodal utterances, including co-speech gestures. As a consequence, the status of pronominal pointing might shift to a relative modality effect because it exists in both modalities in some form, although its status and use are quite different between the modalities. We have found several other putative absolute modality effects, too, where interpretation depends on analytical and definitional choices. Making these choices and their consequences explicit will be one of the important tasks in the conceptual development of cross-modal typology.

Furthermore, the issue of multimodality is not limited to spoken languages but also affects sign languages. In addition to the manual and non-manual components that are the most prominent carriers of meaning, sign languages also include sub-systems that are the result of contact with other modalities. A case in point is the use of mouth movements derived from the visible articulation of spoken words (so-called 'mouthings', see Boyes Braem \& Sutton-Spence 2001). Mouthings play an important functional role in some, though by no means all, sign languages. Moreover, those sign languages that 
have been in contact with literacy, particularly via school education, use manual alphabets ('fingerspelling') which constitute another sub-system with distinct properties such as handshapes that do not necessarily occur elsewhere in the language.

Handshapes that are peripheral to the phonological system of sign languages are also regularly found in numeral signs that iconically reflect the shape of written numbers (see Figure 12). The relationship between a written symbol and a linguistic form is a challenge to comparability between signed and spoken languages. Presumably, this kind of iconicity would have to be classified as an absolute modality effect of the 'a priori' type, since there is no way that speech sounds can iconically reflect written symbols, and we would argue that this is a particularly interesting feature of sign languages.

However, one might also posit that such narrowly circumscribed sub-systems may better be excluded from comparisons, to the extent that their status in the language. In any case, is peripheral (e.g. Brentari \& Padden (2001) argue that fingerspelling in ASL is outside of the core, native lexicon). The phenomenon of iconically motivated numerals with phonologically peripheral handshapes is a local crossover effect, where the contact situation with another semiotic type, in this case in the form of written symbols, interacts with the semiotic performances of sign languages. The numeral handshapes are a particularly conspicuous example of contact between different modalities, but many other effects of such contact are also common, including calques and the abovementioned mouthings. In the semiotic ecosystems of a speaker or signer, the lived reality is often more complex than the presumed dichotomy between the auditory-vocal form of language on the one hand and the visual-gesture form of language on the other hand, and this is an issue that deserves further study.

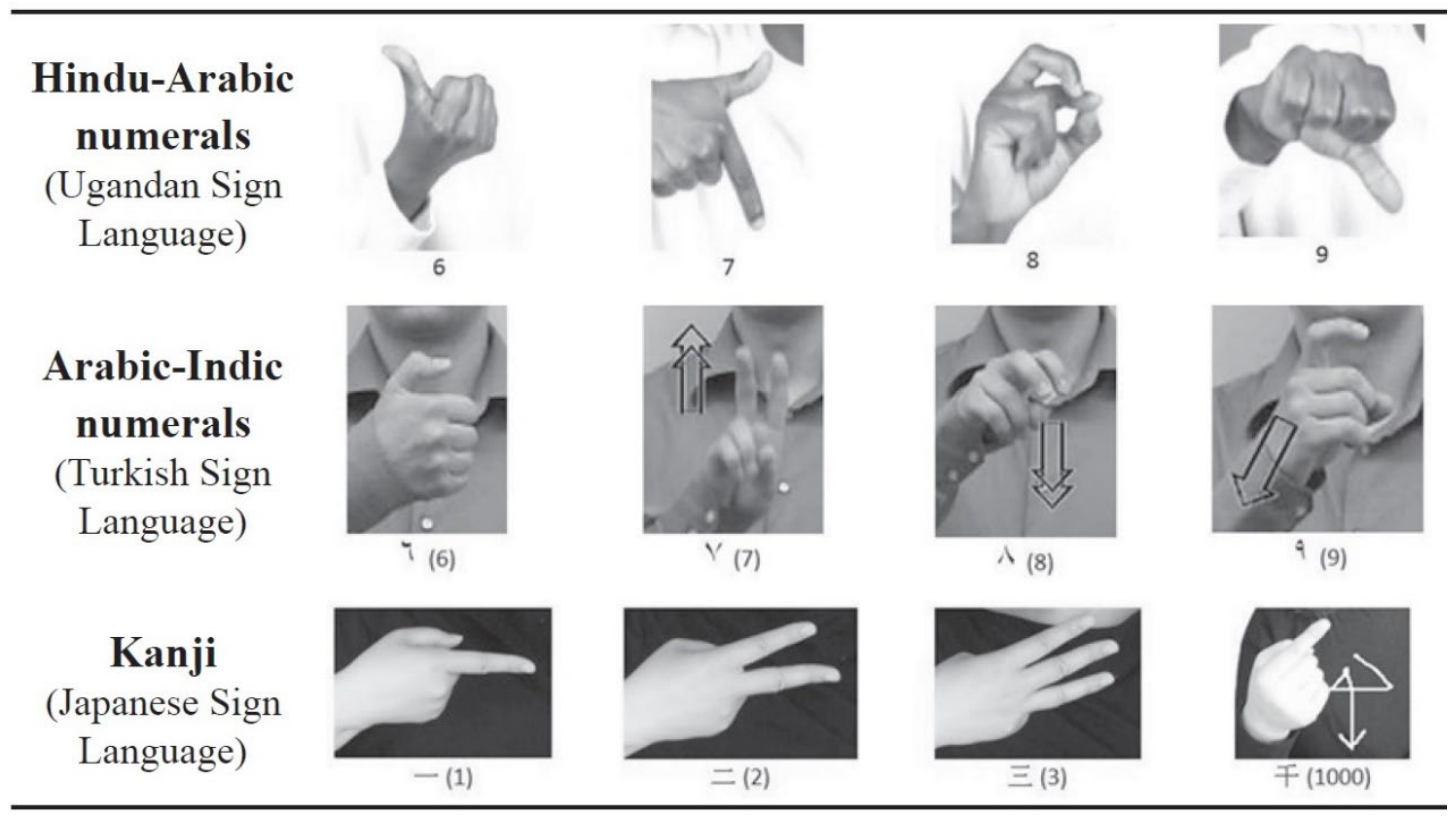

Figure 12. Numerals in three sign languages based on writing systems (from Sagara \& Zeshan 2016: 28)

In this article, we have taken the view that cross-modal typology must base hypotheses about modality effects on substantial linguistic diversity in both signed and spoken languages. Therefore, it is encouraging that some principled efforts are underway in sign language linguistics to increase available data that will be specifically useful to typologists. A European collaboration (the SignGram project) has produced a generic blueprint for the compilation of reference grammars of sign languages (Quer et al 2017). This initiative is now being followed by the SIGN-HUB project, through which researchers, guided by the blueprint, are beginning to work on producing reference grammars of six individual sign languages in Germany, Catalonia, Spain, Italy, the Netherlands, and Turkey. At the same time, the number of digital resources in sign languages, both as individual languages and cross linguistically, is continuously expanding. Alongside an increasing number of sign language corpora, there are also efforts 
such as the Global Signbank, ${ }^{15}$ a cross-linguistics lexical database for sign languages. We can be optimistic that, in the near future, we will see substantial developments with respect to both conceptual and data-driven developments in cross-modal typology.

\section{Acknowledgements}

We would like to thank all of the deaf sign language users who have shared information about their sign languages with us. In particular, for the investigation summarised in Section 4, we are grateful to Hasan Dikyuva, Kang-Suk Byun, Qian Sun, Sibaji Panda and Muhammad Isnaini. We received very constructive feedback from several anonymous reviewers, to whom we are indebted and wish to express our gratitude. We would also like to thank Deepu Manavalamamuni, Jagdishkumar Choudhari and Muhammad Isnaini for their help with some of the photographs.

In addition, Palfreyman acknowledges the support of the Leverhulme Trust in granting his Early Career Research Fellowship (ECF-2016-795).

\section{References}

Alm-Arvius, Christina (1993). The English verb see: a study in multiple meaning. Gothenburg: Acta Universitatis Gothoburgensis.

Báez-Montero, Inmaculada C. \& Ana María Fernández-Soneira (2016). Colours and numerals in Spanish Sign Language (LSE). In Ulrike Zeshan \& Keiko Sagara (eds.), Semantic fields in sign languages: Colour, kinship and quantification (Sign Language Typology Series No. 6) (pp. 73-122). Berlin: De Gruyter Mouton \& Lancaster: Ishara Press.

Bakker, Peter (2015). 'Creoles, Creole Studies and Sign Languages', Journal of Pidgin and Creole Languages 30:2, 357-369.

Benczes, Réka (2019). Rhyme over reason: Phonological motivation in English. Cambridge: Cambridge University Press.

Blust, Robert (2003). The phonestheme N-in Austronesian languages. Oceanic Linguistics 42(1): 187212.

Bottari, Davide, Anne Claclin, Marie-Hélène Giard and Francesco Pavani (2011). Changes in early cortical visual processing predict enhanced reactivity in deaf individuals. PLoS ONE 6:9, 1-10.

Boyes Braem, Penny \& Rachel Sutton-Spence (eds.) (2001). The Hands are the Head of the Mouth: The Mouth as Articulator in Sign Languages. Hamburg: Signum.

Brentari, Diane (1998). A prosodic model of sign language phonology. Cambridge, MA: MIT Press.

Brentari, Diane (2002). Modality differences in sign language phonology and morphophonemics. In Meier, Richard, Kearsy Cormier \& David Quinto-Pozos (eds.), Modality and structure in signed and spoken languages (pp. 35-64). Cambridge: CUP.

Brentari, Diane \& Carol Padden (2001). Native and foreign vocabulary in American Sign Language: A lexicon with multiple origins. In Diane Brentari (ed.) Foreign vocabulary: A cross-linguistic investigation of word formation, Mahwah, NJ: Lawrence Erlbaum Associates, 87-119.

Cinque, Guglielmo (1999). Adverbs and functional heads: A cross-linguistic perspective. New York: Oxford University Press.

Comrie, Bernard (2013). Numeral Bases. In: Dryer, Matthew S. \& Haspelmath, Martin (eds.) The World Atlas of Language Structures Online. Leipzig: Max Planck Institute for Evolutionary Anthropology. (Available online at http://wals.info/chapter/131, Accessed on 2019-02-03.)

Costello, Brendan, Javier Fernández \& Alazne Landa. 2008. The non-(existent) native signer: Sign language research in a small deaf population. In Ronice Muller de Quadros (ed.) Sign Languages: Spinning and Unravelling the Past, Present and Future. Forty-five papers and three posters from TISLR9. Petrópolis: Editora Arara Azul, 77-94.

Crasborn, Onno (2010). The Sign Linguistics Corpora Network: Towards Standards for Signed Language Resources. Proceedings of 7th International Conference on Language Resources and Evaluation (LREC), Malta, 17 May 2010. pp. 457-460

${ }^{15}$ See https://signbank.science.ru.nl/ [accessed 03 Nov 2019] 
Cuxac, Christian (2000). "Compositionnalité sublexicale morphémique-iconique en langue des signes française." Recherches linguistiques de Vincennes 29: 55-72.

de Vos, Connie (2012). Sign-Spatiality in Kata Kolok: How a village sign language of Bali inscribes its signing space. PhD dissertation, Max Planck Institute of Psycholinguistics, Nijmegen.

de Vos, Connie, \& Roland Pfau (2015). Sign Language Typology: The contribution of rural sign languages. Annual Review of Linguistics 1: 265-288.

Deuchar, Margaret (1986). Sign languages as creoles and Chomsky's notion of universal grammar. In Sohan Modgil \& Celia Modgil (eds.) Noam Chomsky consensus and controversy (pp. 81-91). Brighton: Falmer Press.

Dingemanse, Mark, Damian E. Blasi, Gary Lupyan, Morten H. Christiansen, Padraic Monaghan (2015). Arbitrariness, Iconicity, and Systematicity in Language. Trends in Cognitive Sciences, October 19(10), 603-615.

Dryer, Matthew S. (2013). Negative Morphemes. In: Dryer, Matthew S. \& Haspelmath, Martin (eds.) The World Atlas of Language Structures Online. Leipzig: Max Planck Institute for Evolutionary Anthropology. (Available online at http://wals.info/chapter/112, Accessed on 2019-02-03.)

Enfield, Nick J. (2013). A 'Composite Utterances' approach to meaning. In: Cornelia Müller, Ellen Fricke, Alan J. Cienki, Silvia H. Ladewig, David McNeill and Sedinha Teßendorf (eds.) Body - Language Communication: An International Handbook on Multimodality in Human Interaction, Volume 1. Berlin: De Gruyter, 689-706.

Evans, Nicholas and David P. Wilkins (2000). In the mind's ear: The semantic extensions of perception verbs in Australian languages. Language 76:3, 546-592.

Firth, John R. (1930). Speech. In: John R. Firth (1964) The Tongues of Men and Speech. London: Oxford University Press.

Fischer, Susan (1978). Sign languages and creoles. In Patricia Siple (ed.), Understanding language through sign language research (309-331). New York: Academic Press.

Green, Jennifer (2016). Multimodal complexity in sand story narratives. Narrative Inquiry 26(2): 312339.

Haiman, John (1985). Natural Syntax: Iconicity and Erosion. Cambridge: Cambridge University Press.

Haiman, John (2017). Ideophones and the Evolution of Language. Cambridge: Cambridge University Press.

Heine, Bernd (1997). Possession: Cognitive sources, forces, and grammaticalization. Cambridge: Cambridge University Press.

Hodge, Gabrielle, Lindsay N. Ferrara and Benjamin D. Anible (2019). The semiotic diversity of doing reference in a deaf signed language. Journal of Pragmatics, Vol. 143, 33-53.

Jirak, Doreen, Mareike M. Menz, Giovanni Buccino, Anna M. Borghi \& Ferdinand Binkofski (2010). Grasping language-a short story on embodiment. Consciousness and cognition 19(3): 711-720.

Johnston, Trevor (2018). The role of headshake in negation in Auslan (Australian Sign Language): Implications for signed language typology. Linguistic Typology 22(2): 185-231. doi.org/10.1515/lingty-2018-0008

Johnston, Trevor and Adam Schembri (1999). On defining lexeme in a signed language. Sign language and Linguistics 2:115-185.

Johnston, Trevor and Lindsay Ferrara (2012). Lexicalisation in Signed Languages: When is an Idiom not an Idiom? Proceedings of the 3rd UK Cognitive Linguistics Conference, University of Hertfordshire, 6-8 July 2010.

Kwon, Nahyun \& Erich R. Round (2015). Phonaesthemes in morphological theory. Morphology 25: 127.

Lakoff, George \& Mark Johnson (2003[1980]). Metaphors we live by. Chicago: The University of Chicago Press.

Liddell, Scott K. (2003). Grammar, gesture, and meaning in American Sign Language. Cambridge University Press.

Lillo-Martin, Diane (1999). Modality effects and modularity in language acquisition: The acquisition of American Sign Language. In Ritchie, William, \& Tej Bhatia (eds.) Handbook of child language acquisition (pp. 531-567). Leiden: Brill.

Lindström, Eva (2002). Topics in the grammar of Kuot, a non-Austronesian language of New Ireland, Papua New Guinea. PhD dissertation, Stockholm University. 
Lupton, Linda, \& Joe Salmons (1996). A re-analysis of the creole status of American Sign Language. Sign Language Studies 90: 80-94.

Lutalo-Kiingi, Sam (2014). A descriptive grammar of morphosyntactic constructions in Ugandan Sign Language (UgSL). PhD thesis, University of Central Lancashire, Preston, UK.

Lutzenberger, Hannah (2018). The emergence of phonology within six generations, MA dissertation, Radboud University, Nijmegen.

Majewicz, Alfred (1984). Le rôle du doigt et de la main et leurs désignations en certaines langues dans la formation des systèmes particuliers de numération et des noms de nombre. Lingua Posnaniensis 28:69-84.

McBurney, Susan (2012). History of sign languages and sign language linguistics. In Pfau, Roland, Markus Steinbach, and Bencie Woll (eds.) Sign language: An international handbook. Vol. 37. Berlin a.o.: Walter de Gruyter, pp. 909-948.

McKee, Rachel (2015). New Zealand Sign Language: A Reference Grammar. Wellington: Bridget Williams Books Ltd.

Meier, Richard, Kearsy Cormier and David Quinto-Pozos (eds.) (2002). Modality and Structure in Signed and Spoken Languages. Cambridge: Cambridge University Press.

Michaelis, Susanne, Philippe Maurer, Martin Haspelmath, \& Magnus Huber (2013). The atlas of pidgin and creole language structures. Oxford: Oxford University Press.

Miles, Michael (2000). Signing in the Seraglio: mutes, dwarfs and jestures at the Ottoman Court 15001700. Disability \& Society 15(1): 115-134.

Nyst, Victoria (2012). Shared Sign Languages. In Pfau, Roland, Markus Steinbach, and Bencie Woll (eds.) Sign language: An international handbook. Vol. 37. Berlin a.o.: Walter de Gruyter.

Oomen, Marloes \& Pfau, Roland (2017). Signing NOT (or not): A typological perspective on standard negation in Sign Language of the Netherlands. Linguistic Typology 21(1): 1-51. doi:10.1515/lingty2017-0001

Palfreyman, Nick (2019). Variation in Indonesian Sign Language: A typological and sociolinguistic analysis. Sign Language Typology [SLT] 8. Berlin: De Gruyter Mouton.

Pfau, Roland (2008). The grammar of headshake: A typological perspective on German Sign Language negation. Linguistics in Amsterdam 1: 37-74.

Pfau, Roland \& Markus Steinbach (2006). Pluralization in sign and in speech: A cross-modal typological study. Linguistic Typology 10(2): 135-182.

Pfau, Roland \& Markus Steinbach (2011). Grammaticalization in sign languages. In Heiko Narrog \& Bernd Heine (eds.), The Oxford handbook of grammaticalization (pp. 681-693). Oxford: Oxford University Press.

Pfau, Roland \& Markus Steinbach (2013). Headshakes in Jespersen's Cycle. Paper presented at the 11th Conference on Theoretical Issues in Sign Language Research (TISLR 11), London, July 10.

Pfau, Roland, Markus Steinbach, \& Annika Herrmann (2016). A matter of complexity: Subordination in sign languages. (Sign Language and Deaf Communities 6.) Berlin: De Gruyter Mouton.

Poizner, Howard, Edward S. Klima, \& Ursula Bellugi (1990). What the hands reveal about the brain. Cambridge (Mass.), MIT Press.

Quer, Josep, Carlo Cecchetto, Caterina Donati, Carlo Geraci, Meltem Kelepir, Roland Pfau, \& Markus Steinbach (2017). SignGram Blueprint. A Guide to Sign Language Grammar Writing. Berlin a o: De Gruyter Mouton.

Sandler, Wendy (2012). The phonological organization of sign languages. Language and Linguistics Compass. 6(3): 162-182. doi:10.1002/lnc3.326.

Schembri, Adam, Jordan Fenlon, Kearsy Cormier, \& Trevor Johnston (2018). Sociolinguistic typology and sign languages. Frontiers in Psychology 9: 200. doi: 10.3389/fpsyg.2018.00200

Senghas, Ann (2005). Language emergence: Clues from a new Bedouin sign language. Current Biology, $15: 12,463-465$.

Speed, Laura J., Carolyn O'Meara, Lila San Roque, \& Asifa Majid (eds.) (2019). Sensory Perception Metaphors. Amsterdam: John Benjamins.

Stokoe, William (1960). Sign language structure: An outline of the visual communication systems of the American deaf. Studies in Linguistics, Occasional Papers 8, Department of Anthropology and Linguistics, University of Buffalo, Buffalo 14, New York. 
Supalla, Ted, \& Rebecca Webb (1995). The grammar of International Sign: A new look at pidgin languages. In Karen Emmorey \& Judy Reilly (eds.) Sign, gesture and space. Mahwah, NJ: Lawrence Erlbaum.

Sweetser, Eve (1990). From etymology to pragmatics: The mind-body metaphor in semantic structure and semantic change. Cambridge, MA: Cambridge University Press.

Tang, Gladys (ed.) (in prep.). A reference grammar of Hong Kong Sign Language. Sign Language Typology Series No. 10. Lancaster: Ishara Press and Berlin a.o.: De Gruyter.

Tomaszewski, Piotr (2015). Constraints on negative prefixation in Polish Sign Language. PLoS ONE 10(11): e0143574.

Whynot, Lori A. (2016). Understanding International Sign: A sociolinguistic study. Washington, DC: Gallaudet University Press.

Wilbur, Ronnie B. (2000). Phonological and prosodic layering of non-manuals in American Sign Language. In Karen Emmorey \& Harlan Lane (eds.), The signs of language revisited: An anthology to honour Ursula Bellugi and Edward Klima (pp. 213-244). Mahwah, NJ: Lawrence Erlbaum.

Zeshan, Ulrike (2002). Towards a Notion of 'Word' in Sign Languages. In: Dixon, Robert M.W. and Alexandra Y. Aikhenvald (eds.) Word: A cross-linguistic typology. Cambridge University Press, pp. 153-179.

Zeshan, Ulrike (2003). Aspects of Türk İşaret Dili (Turkish Sign Language). Sign Language \& Linguistics 6(1): 43-75.

Zeshan, Ulrike (2004). Hand, head and face: Negative constructions in sign languages. Linguistic Typology 8, 1-58.

Zeshan, Ulrike, (ed.) (2006). Interrogative and negative constructions in sign languages. Sign Language Typology Series No. 1. Nijmegen: Ishara Press.

Zeshan, Ulrike (2015). "Making meaning”: Communication between sign language users without a shared language. Cognitive Linguistics 26(2): 211-260.

Zeshan, Ulrike (2017). Comparability between signed and spoken languages. Plenary Panel on Comparability. 12th Conference of the Association for Linguistic Typology (ALT), Canberra, Australia, 11-15 December 2017.

Zeshan, Ulrike \& Pamela Perniss, (eds.) (2008). Possessive and Existential Constructions in Sign Languages. Sign Language Typology Series 2. Nijmegen: Ishara Press.

Zeshan, Ulrike \& Connie de Vos, (eds.) (2012). Sign Languages in Village Communities: Anthropological and Linguistic Insights. Sign Language Typology Series No. 4. Berlin: De Gruyter Mouton and Nijmegen: Ishara Press.

Zeshan, Ulrike, Cesar Ernesto Escobedo Delgado, Hasan Dikyuva, Sibaji Panda, \& Connie De Vos (2013). Cardinal numerals in rural sign languages: Approaching cross-modal typology. Linguistic Typology 17: 357-396.

Zeshan, Ulrike \& Nick Palfreyman (2017). Sign Language Typology. In A. Y. Aikhenvald and R. M. W. Dixon (eds.), The Cambridge Handbook of Linguistic Typology (pp. 178-216). Cambridge: CUP.

Zeshan, Ulrike \& Nick Palfreyman (2019). Sensory perception metaphors in sign languages. In Laura J. Speed, Carolyn O'Meara, Lila San Roque, \& Asifa Majid (eds.), Sensory Perception Metaphors (pp. 275-302). Amsterdam: John Benjamins.

Zeshan, Ulrike \& Keiko Sagara (eds.) (2016). Semantic Fields in Sign Languages: Colour, Kinship and Quantification (Sign Language Typology Series No. 6). Berlin: De Gruyter Mouton \& Lancaster: Ishara Press.

Zucchi, Sandro (2018). Sign language iconicity and gradient effects. Theoretical Linguistics 44(3-4): 283-294. 